\title{
Introduction Essay: Special Issue of RMDC on Public Scholarship, Media and Religion
}

\author{
Kristin M. Peterson \\ Assistant Professor, Department of Communication, Chestnut Hill, \\ Boston College, MA, United States \\ petersub@bc.edu
}

\author{
Heidi A. Campbell \\ Professor, Department of Communication, Texas A\&M University, College \\ Station, Texas, United States \\ heidic@tamu.edu
}

\section{Keywords}

Digital media - religion - public scholarship

Public scholarship has become a buzzword among colleges and universities that increasingly encourage their faculty to translate and share their research to a broader public beyond the academy through media outlets. Scholars of media, culture, and religion are well placed to do this work, by showing how their focused research in these areas enables them to speak to and offer commentary on current political and cultural events in society. The 2018 conference of the International Society for Media, Religion, and Culture (ISMRC) focused on this theme, considering the challenges and opportunities created by doing public scholarship that speaks to the relationship between media and religion. While there are benefits to making scholarship about topics like media and religion accessible to a general audience, challenges arise when academics enter public spaces that contain their own particular communication structures, pressures and expectations. Papers and keynotes presented at the ISMRC conference revealed significant interconnections regarding how media and religion interact and impact one another. Scholars are increasingly pushed to prove the public relevance of their work; religions compete with other cultural institutions for recognition and a voice; and media provide useful tools and productive spaces for scholars and religious leaders to do this work of demonstrating relevance. 
Scholars also face neoliberal market pressures to self-brand and quantify their results as profitable. These pressures, in turn, influence how scholars do their work, as well as the subjects of academic research. At the same time, the move towards public scholarship is also driven by demands for scholars to calculate the impact of their academic research, through tracking not only scholarly citations, but public and media engagement with their work. For instance, in co-editor Kristin Peterson's current research on intersectional feminist activism among Muslim and Christian women online, several of the participants are accustomed to working with academics along with community organizers and digital activists. These participants see academic scholarship in books and articles as part of a larger public project of writing popular press books, circulating articles and connecting on social media in order to organize for political change. Similarly, co-editor Heidi A. Campbell notes in her current research on religious digital creatives and how they act as a new form of religious authority that it is important for scholars to have an active online presence, as one's digital profile can create and open or close doors for interaction with everyday people and especially media professionals.

The essays and research articles in this special issue build on the themes and theories that were discussed at the ISMRC conference in August 2018 regarding the institutional promotion of and move towards public scholarship for media and religion scholars. The diverse contributions in this issue address what public scholarship looks like and how it impacts this field of study from a variety of cultural contexts, including North America, Europe, West Africa, East Asia, and the Middle East. Furthermore, the cases address a variety of religious and secular traditions, along with emerging and established media forms, such as mobile apps, video games, podcasts, journalism, social media and online forums.

This introductory essay focuses on two main themes discussed throughout this special issue. First, many authors highlight specific challenges and opportunities that scholars face when they do public scholarship by engaging with religious subjects in public spaces, as well as by circulating research for a public audience through digital media channels. Second, the research articles in particular focus on the negotiations made by religious practitioners and leaders who seek to engage with emerging digital media spaces and tools to reach a variety of media-driven audiences. The contributions in this special issue illustrate the complex dynamics at play as academics study how people use digital media to reach various publics while scholars themselves also attempt to illustrate the public significance of their work. Both scholars and research participants are becoming more self-reflexive of the prospects and limitations of public-facing research. 


\section{Opportunities and Limitations of Public Scholarship on Media and Religion}

Emerging digital media spaces are increasingly becoming the main avenues for media and religion scholars to engage with research subjects and collaborators along with public audiences who might benefit from this research. The opening multi-authored forum article, "Global Perspectives on Religion, Media and Public Scholarship," addresses the particular challenges of being a public scholar of religion in three distinct contexts: West Africa, Europe, and East Asia. Each of the scholars in this forum reflects on the unique dynamics scholars of religion must engage with and balance as they are called on to make their research public, and as they study groups who are also working to make their religious messages public. As Hutchings explains, "we are simultaneously public scholars and scholars of publicness. We mediate subjects who are already mediating themselves" (page 150). Research participants are more comfortable being the subjects of public scholarship and journalism, and they often see the benefits of participating in public scholarship projects by extending the public-facing work that they are already doing.

The relationship between religion, media, and public scholarship looks different depending on the cultural and political context. As Asamoah-Gyadu discusses in the context of West Africa, religion is prominently displayed in public life and openly discussed in news media and culture. For example, the globalized economy promotes more migration for economic opportunity, and these ideas of success are increasingly connected to a Prosperity Gospel interpretation of Christianity. Asamoah-Gyadu discusses an "age of desperation" in which people believe that Christianity will provide prosperity and escape from failed economic and political situations in many African countries (page 152). Furthermore, religion has extensive connections to media in African contexts; Christian preachers and new religious leaders use media technologies to convey the power of the divine realm.

This global forum challenges the assumption that there is a universal understanding of the role religion plays in public spaces. Evolvi's discussion of the secular public spaces in Europe is put into conversation with Han's reflections on the public role of religion in Singapore. In an effort to decentralize a Western European understanding of religion and public life, Han asserts that in Singapore the need to maintain "religious harmony" is more important than having the freedom to offend people with your religious beliefs. The position of religion within public space and how religious issues can be discussed within public media spaces varies greatly depending on the political and cultural context. 
This global forum also discusses the challenges of doing public scholarship, especially when studying religious groups that are often misunderstood by the public or make themselves too visible or too political in public spaces. For instance, Evolvi discusses how European spaces are challenged in distinct ways by the public presence of Muslims, atheist activists, and conservative Catholic groups. While these groups have often been silenced in traditional public spaces, they find platforms of expression through digital media and often are emboldened to push these viewpoints into offline spaces. Evolvi discusses the practical challenges of studying such expansive media spaces and also the personal struggles of conducting research on groups that engage with ideological extremes in order to break into public consciousness.

Along the same lines, other contributions to this special issue also address conducting research about publics that incorporates controversial groups and contentious political debates. Winston's essay reflects on her personal experience teaching journalism students how to ethically and fairly cover religious topics. She discusses a course collaboration between the students at her secular journalism school and students at an Evangelical Christian school. This course experiment was an attempt to get beyond the polarization between Christian Americans and non-religious journalists. Winston's promotion of "public theology" is a helpful reminder that academic research should be conducted for the common good and motivated by shared religious and secular values.

While religious ideology is often misconstrued as more extreme and irrational in Western cultures, Rifai's research article on pro-anorexia digital communities is a significant reminder that secular movements are not necessarily rational or mainstream. Rifai details how the early "pro-ana" online forums frequently incorporated religious terms, belief in the divine, prayers, and creeds. Although the more recent pro-ana digital communities reject religious rhetoric, Rifai argues that these online expressions often incorporate Protestant ideologies of "individualism, self-control and mastery" (page 207). Academic studies of extreme and widely-detested public groups like pro-ana communities are difficult and require care to not appear to condone these ideologies. At the same time, it is significant to understand how religious and secular ideologies infuse different public spaces and expressions.

\section{Negotiation of Digital Media and Public Spaces}

As noted above, the second theme that is addressed in the special issue is how religious practitioners and leaders engage with new media forms in emerging 
public spaces. Popular media become tools to help them reach new followers, to spread religious messages, to formulate meaning, and to create communities. These articles reflect on how digital media provide innovative opportunities for religions to reach their own practitioners, but also to communicate with wider publics. Yet digital media challenge traditional religious authorities by offering new spaces for community and alternative modes of creating religious meaning.

This is seen in Stanton's article, which discusses the mobile applications that are created by the Saudi government in order to offer practical information for those few Muslims who are able to go on the annual Hajj pilgrimage to Mecca. Since it is a once in a lifetime experience to go on the Hajj, the apps are developed to ensure all the aspects go smoothly. Stanton addresses some of the critiques of the apps, such as that the government uses the apps to monitor and control the pilgrims or that using a mobile app will distract the participants away from the spiritual experience of the pilgrimage. While the mobile apps are currently sanctioned as useful tools that shouldn't distract from the spiritual experience, Stanton addresses how the religious leaders don't approve of the development of apps that would recreate the Hajj for the millions of Muslims who can never attend the pilgrimage.

Similarly, Gottlieb's article addresses how two Reformed Jewish rabbis negotiated the ways a digital video game could be used for religious education and rituals. In this case, a boy on the Autism spectrum was allowed to use the video game Minecraft to prepare for his Bar Mitzvah and also to perform the sermon portion of the Bar Mitzvah ritual. Gottlieb acknowledges the extensive academic research on how Orthodox Jewish rabbis negotiate with new media technologies to enable them to be incorporated into their daily lives and religious rituals. Yet this article is original in its focus on Reformed Jewish rabbis, an understudied group within religion and media studies. Gottlieb addresses how these rabbis find the video game to be a useful religious education tool. First, using Minecraft to teach religious concepts is part of a Reformed Jewish tradition to meet students where they are gathering and to use the same digital language. Second, this was a specific case in which the video game was used to help a student with neurological differences and this fits into the inclusive mission of progressive Jewish communities.

While digital media may provide new spaces for emerging religious communities, the essay from Mahan stresses how mainline Protestant congregations are increasingly called upon to adapt to new forms of meaning making and rituals in this digital moment. Mahan critically reflects not only on the digital tools that congregations use to reach followers, but also how the culture of digital media spaces shifts religious meaning, community, authority, and theology. 
Through a discussion of an alternative Christian community in Denver, Mahan explores how online spaces enable new ways of living a Christian life in community with others. Public scholarship like Mahan's research on digital congregations provides practical strategies for religious leaders to create hybrid spaces for communities to gather and perform collective rituals.

Finally, Fekete and Knippel present their research on podcast communities created around groups of former Evangelical Christians, and so explore the ways in which digital media offer alternative community spaces for those recovering from traumatic religious experiences. In this article, they assert that this ex-Evangelical community would not be so vibrant and active without social media and podcasts providing open spaces for discussion, debate, and support. Within Evangelical Christianity, a larger faith community is necessary for creating a new tradition. Therefore, the authors explore the ways that communities are still significant for those deconstructing their Evangelical faith. Fekete and Knippel write, "The support of a localized community is an integral part of the process of joining a faith tradition. Given this, it would stand to reason that there is a need and benefit for a similar community when one is going through a process of critiquing or exiting from their existing faith tradition" (page 165). Digital media, in this case, provide a community of support for those marginalized from mainstream public spaces.

\section{Conclusion}

The case studies presented in the research articles in this special issue illustrate the various ways that religious groups, both institutional leaders and marginalized outsiders, attempt to use public spaces to demonstrate the significance of certain perspectives. Digital media increasingly provide new avenues for this public-facing work. However, sometimes the crowded cacophony of these online spaces pushes more creative public projects to adapt to or interact with traditional public spaces and established news media. Scholars of media and religion also are called upon to enter into these public spaces, both to study these groups that are active in public media channels and also to leverage media to demonstrate the public relevance of their research on media, religion and culture. The contribution of this special issue is to demonstrate and draw attention to struggles that scholars and research participants face as they enter into these public and media-laden spaces, hoping to have a social and political impact. Through this special issue we highlight that digital media does more than just provide tools that enable new forms of collaborative research between research participants and scholars. These emerging media spaces 
offer new avenues for the circulation of scholarship that can enable scholars to speak into larger cultural, social and political spaces. This scholarly work, when it is collectively organized and translated, can move beyond the academy in ways that illuminate how digital media are influencing the contemporary public. 